\title{
Factors related to on-treatment platelet aggregation assessed by multiple electrode aggregometry in percutaneous coronary intervention patients on clopidogrel and aspirin
}

\author{
Krzysztof Kukula ${ }^{1}$, Mariusz Klopotowski ${ }^{1}$, Joanna Was ${ }^{2}$, Aleksandra Wrobel ${ }^{2}$, Jacek Jamiolkowski ${ }^{3}$, \\ Artur Debski ${ }^{1}$, Pawel Bekta ${ }^{1}$, Zbigniew Chmielak ${ }^{1}$, Adam Witkowski ${ }^{1}$ \\ ${ }^{1}$ Department of Interventional Cardiology and Angiology, Institute of Cardiology, Warsaw, Poland \\ ${ }^{2}$ Department of Medical Biology, Institute of Cardiology, Warsaw, Poland \\ ${ }^{3}$ Department of Public Health, Medical University of Bialystok, Bialystok, Poland
}

Adv Interv Cardiol 2017; 13, 3 (49): 210-217

DOI: https://doi.org/10.5114/aic.2017.70188

\begin{abstract}
Introduction: There is ongoing controversy concerning the clinical value of platelet function monitoring in patients undergoing percutaneous coronary interventions (PCI). Patients at risk of high on-treatment platelet aggregation (HPR) may benefit most from such monitoring.

Aim: To define the factors related to HPR on aspirin and clopidogrel, looking at a wider spectrum of variables than those assessed in some previous studies.

Material and methods: We assessed platelet function in 908 patients on clopidogrel and aspirin after $\mathrm{PCl}$ using the multielectrode aggregometry system Multiplate to define which clinical, procedural and laboratory factors are related to on-treatment platelet aggregation in response to aspirin and clopidogrel either as linear values or using established cutoff values for HPR.

Results: We found that in $\mathrm{PCl}$ patients on clopidogrel and aspirin, age (OR per year 1.06; 95\% Cl: 1.024-1.097; $p=0.001)$, gen$\operatorname{der}(\mathrm{OR}=0.319 ; 95 \% \mathrm{Cl}: 0.139-0.731 ; p=0.007)$, active smoking $(\mathrm{OR}=2.57 ; 95 \% \mathrm{Cl}: 1.29-5.15 ; p=0.008)$, diabetes $(\beta=37.6$; $95 \% \mathrm{Cl}: 16.5-58.8 ; p=0.001)$ and hypertension $(\beta=26.9 ; 95 \% \mathrm{Cl}: 6.73-47.1 ; p=0.009)$ are independently linked to platelet aggregation values treated as linear values and as dichotomous variables at the accepted cutoffs. The same is true for stented segment length (OR per $\mathrm{mm} \mathrm{1.033;95 \%} \mathrm{Cl:} \mathrm{1.010-1.057;} p=0.009$ ) and stent inflation pressure (OR per atmosphere 0.862; 95\% Cl: 0.772-0.963; $p=0.002$.

Conclusions: The study shows that, contrary to some earlier data, in the tested cohort women are better clopidogrel responders, but more often aspirin low-responders. Older age, active smoking, diabetes and hypertension all predispose to HPR. A novel finding is that stented segment length is an independent predictor of lower response both to aspirin and clopidogrel, possibly as a marker of more diffuse atherosclerosis.
\end{abstract}

Key words: platelet, aggregation, reactivity, coronary intervention, risk factors, Multiplate, clopidogrel.

\section{Introduction}

Percutaneous coronary interventions $(\mathrm{PCl})$, either in the setting of stable coronary artery disease (CAD) or in acute coronary syndromes (ACS), have become very common procedures in cardiology $[1,2]$. While in patients with ACS the use of newer antiplatelet agents is now advocated, clopidogrel remains the mainstay of dual antiplatelet therapy (DAPT) in elective procedures, and in many countries, also in ACS [3-5]. Despite its efficacy, about $2 \%$ to $5 \%$ of patients experience stent thrombosis or recurrent ischemic events in the first year following the procedure [6]. On the other hand, the treatment increases the risk of bleeding [7]. Numerous studies have been undertaken attempting to define the safety and efficacy profile of DAPT in different patient populations, and a number of platelet reactivity assessment methods for clinical use are available, but at present none are recommended for routine patient evaluation and treatment

\section{Corresponding author:}

Krzysztof Kukula MD, PhD, Department of Interventional Cardiology and Angiology, Institute of Cardiology, 42 Alpejska St, 04-628 Warsaw, Poland, phone: +48 2234342 72, fax: +48 2261338 19, e-mail: krzysiokuk@yahoo.com

Received: 11.06 .2017 , accepted: 12.06 .2017$. 
[8-10]. Depending on the method of assessment, it is estimated that up to $20-30 \%$ of patients on clopidogrel are insufficiently responsive to the drug [11]. A number of factors - clinical, genetic and others - are thought to influence platelet reactivity in patients on DAPT; many have been investigated, but their significance still remains a matter of controversy [12]. While observational studies quite uniformly link clopidogrel underresponse with increased risk of thrombosis or ischemia, the few controlled trials do not support this [13-17]. Overall though, there is accumulating evidence that monitoring platelet aggregation in patients on DAPT may identify those at risk for stent thrombosis and recurrent ischemia as well as those at increased risk for bleeding $[18,19]$. Clinical guidelines do not advocate routine platelet aggregation monitoring [1, 20, 21]. Hence, we attempted to define the main factors influencing platelet aggregation in patients undergoing $\mathrm{PCl}$ in order to delineate the population of patients at risk - in whom platelet reactivity monitoring could be of most benefit.

\section{Aim}

The aim of this study was to ascertain which clinical or laboratory factors significantly correlate with ADP-induced platelet reactivity measured by multiple electrode platelet aggregometry (MEA).

\section{Material and methods}

A total of $908 \mathrm{PCl}$ patients (654 men) were enrolled in this study. Patients were recruited in the years 20122014. The study protocol was approved by the local Ethical Review Board and the study was conducted in accordance with the Declaration of Helsinki. All patients signed informed consent in order to participate in the study. The study was financed by National Science Centre grants NN 402381438 and NN 403397239.

The studied cohort included patients with stable CAD and ACS patients. Patients on chronic anticoagulants or medications known to influence platelet aggregation (such as Ilb/IIla inhibitors, non-steroid anti-inflammatory agents or steroids) were excluded.

All patients were pretreated with clopidogrel. The ACS patients were loaded with $600 \mathrm{mg}$ of clopidogrel either prior to or immediately after admission and received $300 \mathrm{mg}$ of acetylsalicylic acid (ASA). Stable CAD patients were either pretreated with clopidogrel and ASA for at least three days prior to the procedure or similarly loaded. All patients were subsequently treated with acetylsalicylic acid and clopidogrel at a daily dose of $75 \mathrm{mg}$ each. Angiography and $\mathrm{PCI}$ procedures were performed according to the guidelines of the European Society of Cardiology [20], with no restriction as to stent selection, which was left to the discretion of the operator. Post-dilatation with non-compliant balloons for procedure optimization was strongly encouraged.

\section{Platelet function assessment}

ADP-induced platelet reactivity assessment was performed directly prior to patient discharge, but no earlier than on day three after admission, meaning at least 3 days after loading. The multiple electrode platelet aggregometry (MEA) analyzer Multiplate (Dynabyte, Munich, Germany) was used. The method has been described several times previously [19, 22, 23]. In short, $3 \mathrm{ml}$ of whole blood is collected into a tube containing a direct thrombin inhibitor. All analyses were performed between $30 \mathrm{~min}$ and $3 \mathrm{~h}$ after collecting blood. After dilution with saline and agitation while incubating at $37^{\circ} \mathrm{C}$ for $3 \mathrm{~min}$ in test cuvettes, $6.4 \mu \mathrm{mol}$ of ADP was added. Platelet aggregation was recorded continuously for 6 min and plotted against time in AU $\times$ min arbitrary units representing the area under the curve (ADPtest). The test result was the average of two parallel measurements.

The same analyzer was also used to assess platelet response to acetylsalicylic acid (ASA). In this case $0.5 \mathrm{mM}$ solution of arachidonic acid was used as the agonist (ASPItest).

According to the international consensus statement [24], the upper cutoff MEA values for ADP-induced platelet aggregation and arachidonic acid-induced platelet aggregation were $468 \mathrm{AU} \times \min$ and $203 \mathrm{AU} \times$ min, respectively. Higher platelet aggregation values were considered high on-treatment platelet aggregation (HPR). The lower cutoff value of the ADPtest was accepted as $188 \mathrm{AU} \times \mathrm{min}$. As there is controversy as to the lower cutoff of the ASPItest, we did not use this value in our analyses. We also analyzed the ADPtest and ASPItest values as linear parameters.

\section{Statistical analysis}

Relations between quantitative variables were evaluated using Spearman's correlation coefficients. Distributions of ADPtest and ASPItest values were compared between subgroups with the Mann-Whitney test (in the case of two subgroups) or Kruskal-Wallis test (in the case of more than two subgroups). Relationships between the analyzed clinical, procedural and laboratory parameters and the results of the ADPtest and ASPItest were estimated using multiple regression models. Two types of models were used. Linear regression models were applied for ADP and ASPI variables treated as continuous variables, while logistic regression models were used for dichotomized variables. All calculations were performed using IBM SPSS Statistics version 20.0. P-values smaller than 0.05 where interpreted as statistically significant.

\section{Results}

A cohort of 908 patients (654 men) aged $67 \pm 10.5$ years, undergoing $\mathrm{PCl}$, was studied. The main demographic features of the analyzed cohort are shown in Table I. 
Table I. Basic demographic data of the studied cohort

\begin{tabular}{lc} 
Clinical features & Number of patients (\%) \\
\hline Gender (male) & $654(72)$ \\
\hline DM type 2 & $429(47)$ \\
\hline STEMI & $94(10)$ \\
\hline NSTEMI & $105(12)$ \\
\hline eGFR $<30 \mathrm{ml} / \mathrm{min} / 1.73 \mathrm{~m}^{2}$ & $19(2)$ \\
\hline Smoking & $198(22)$ \\
\hline Hypertension & $664(73)$ \\
\hline HPR & $55(6)$ \\
\hline HAR & $94(10)$ \\
\hline Stent type (DES vs. BMS) & $770(85)$
\end{tabular}

STEMI - ST-elevation myocardial infarction, NSTEMI - non-ST elevation myocardial infarction, DM - diabetes mellitus, DES - drug-eluting stent, BMS - bare metal stent, eGFR - estimated glomerular filtration rate, HPR - high on-treatment platelet reactivity (ADPtest > $468 \mathrm{AU} \times \mathrm{min}$ ); HAR - high on-aspirin platelet reactivity - ASPItest.

We assessed the relation of a number of clinical, procedure-related and laboratory factors to ADPtest and ASPItest values, either as dichotomous variables or linear variables.

\section{ADPtest and ASPItest results as numerical variables}

The correlation between clinical (gender, age, hypertension, diabetes, active smoking status, STEMI, NSTEMI), procedural (treated vessel, stent type, size, length, deployment pressure), and laboratory (estimated glomer- ular filtration rate, hemoglobin level, platelet count) parameters and ADPtest as well as ASPItest values treated as linear variables was investigated.

In the case of the ADPtest we found that patients' age (per each year; $\beta=1.5 ; 95 \% \mathrm{Cl}: 0.54-2.39 ; p=0.002$ ), hypertension $(\beta=26.9 ; 95 \% \mathrm{Cl}: 6.73-47.1 ; p=0.009)$, diabetes ( $\beta=37.6 ; 95 \% \mathrm{Cl}: 16.4-58.8 ; p=0.001)$, and smoking status ( $\beta=46.1 ; 95 \% \mathrm{Cl}: 24.2-67.8 ; p<0.0001)$ were independently correlated with ADPtest results. Out of procedural parameters we found stented segment length (per each $\mathrm{mm} ; \beta=0.84 ; 95 \% \mathrm{Cl}: 0.23-1.65 ; p=0.042$ ) and inflation pressure (per each atmosphere; $\beta=-3.62$; $95 \% \mathrm{Cl}$ : from -6.49 to $-0.74 ; p=0.014)$ to be independently correlated with ADPtest result. Out of laboratory findings only platelet count was correlated with ADPtest as a linear variable (per each $\mathrm{G} / \mathrm{l} ; \beta=0.28 ; 95 \% \mathrm{Cl}$ : 0.12-0.43; $p=0.001$; Table II).

The ASPI test values treated linearly were independently correlated with age (per each year; $\beta=0.65$; 95\% Cl: $0.004-1.29 ; p=0.049)$, smoking status $(\beta=$ $31.74 ; 95 \% \mathrm{Cl}: 16.67-46.81 ; p<0.0001)$ and stented segment length (per each $\mathrm{mm} ; \beta=0.94 ; 95 \% \mathrm{Cl}$ : 0.38-1.50; $p=0.001)$ only.

\section{ADPtest and ASPItest results as dichotomized variables}

\section{ADPtest results}

Using the Cox multiple logistic regression model we tested whether clinical (gender, age, hypertension, diabetes, smoking status, STEMI, NSTEMI), procedural (treated vessel, stent type, size, length, deployment pressure) and laboratory (estimated glomerular filtration rate, hemoglobin level, platelet count) variables were independently related to high on-treatment platelet reactivity (HPR),

Table II. Statistically significant correlations of study variables with ADPtest and ASPItest results analyzed as numerical values

\begin{tabular}{|c|c|c|c|c|}
\hline Variable & $\beta$ coefficient & \multicolumn{2}{|c|}{$95 \%$ confidence interval } & $P$-value \\
\hline \multicolumn{5}{|l|}{ ADPtest values: } \\
\hline Age [years] & 1.5 & 0.54 & 2.39 & 0.002 \\
\hline Hypertension & 26.9 & 6.73 & 47.1 & 0.009 \\
\hline Diabetes type 2 & 37.6 & 16.4 & 58.8 & 0.001 \\
\hline Smoking & 46.1 & 24.2 & 67.8 & $<0.0001$ \\
\hline Stented segment length [mm] & 0.84 & 0.23 & 1.65 & 0.042 \\
\hline Inflation pressure [atm] & -3.62 & -6.49 & -0.74 & 0.014 \\
\hline Platelet count [G/l] & 0.28 & 0.12 & 0.43 & 0.001 \\
\hline \multicolumn{5}{|l|}{ ASPItest values: } \\
\hline Age [years] & 0.65 & 0.004 & 1.29 & 0.049 \\
\hline Smoking & 31.74 & 16.67 & 46.81 & $<0.0001$ \\
\hline Stented segment length [mm] & 0.94 & 0.38 & 1.5 & 0.001 \\
\hline
\end{tabular}


defined as the ADPtest result at the higher cutoff, above $468 \mathrm{AU} \times \min$

We found that women had a smaller chance of HPR than men $(\mathrm{OR}=0.319 ; 95 \% \mathrm{Cl}: 0.139-0.0731 ; p=0.007)$. On the other hand, age (OR per each year $1.06 ; 95 \% \mathrm{Cl}$ : $1.024-1.1 ; p=0.001)$, positive smoking status $(\mathrm{OR}=2.573$; $95 \% \mathrm{Cl}: 1.29-5.15 ; p=0.008)$, and platelet count (OR per each G/l 1.007; 95\% Cl: 1.002-1.012; $p=0.008$ ) were all associated with ADPtest result above $468 \mathrm{AU} \times \mathrm{min}$ (HPR). Of interest, HPR was also more frequent in patients in whom the $\mathrm{PCl}$ procedure was performed on the circumflex branch as compared to the left anterior descending branch $(\mathrm{OR}=3.28 ; 95 \% \mathrm{Cl}: 1.54-6.96 ; p=$ 0.002). Out of procedural variables we found that stented segment length (OR per each $\mathrm{mm} 1.033 ; 95 \% \mathrm{Cl}$ : $1.01-$ 1.057; $p=0.004$ ) and stent inflation pressure (OR per each atmosphere $0.862 ; 95 \% \mathrm{Cl}: 0.772-0.963 ; p=0.009$ ) were independently related to HPR.

The relation of the same variables to the lower cutoff of the ADPtest - below $188 \mathrm{AU} \times$ min - was assessed as well. Patients with an MEA result below this value are often termed "enhanced responders" and are thought to be prone to bleeding complications. We found that hypertension, diabetes, smoking and higher platelet count significantly reduced the odds of platelet reactivity being below $188 \mathrm{AU} \times \min$ (details see Table III).

\section{ASPItest results}

We tested the relation of the same set of variables to the higher cutoff of the ASPItest - above $203 \mathrm{AU} \times \min$ (high on-aspirin platelet reactivity - HAR). We found that, conversely to ADPtest values, women had higher odds of inadequate response to aspirin (ASPItest > $203 \mathrm{AU} \times$ $\min )$ than men $(\mathrm{OR}=2.07 ; 95 \% \mathrm{Cl}: 1.22-3.5 ; p=0.007)$. Also, smoking increased the probability of HAR $(\mathrm{OR}=2.5$; 95\% Cl: 1.58-4.23; $p<0.001)$. Stented segment length was the only procedural parameter related to ASPItest $>203 \mathrm{AU} \times \min (\mathrm{OR}=1.024 ; 95 \% \mathrm{Cl}: 1.005-1.042$; $p=0.011)$.

Platelet aggregation values of patients with acute coronary syndromes did not differ from those of elective $\mathrm{PCl}$ patients. No other tested laboratory parameters were correlated with MEA platelet aggregation values.

The main findings of the study are summarized in Tables II and III.

\section{Discussion}

The study is an analysis of possible risk factors related to HPR in an unselected group of PCl patients, where HPR is defined according to the international consensus statement based on data derived from comparable cohorts [24].

Table III. Statistically significant relations of study variables to ADPtest and ASPItest results analyzed as categorical - dichotomous variables

\begin{tabular}{|c|c|c|c|c|}
\hline Parameter & Odds ratio & \multicolumn{2}{|c|}{$95 \%$ confidence interval } & $P$-value \\
\hline \multicolumn{5}{|l|}{ ADPtest > $468 \mathrm{AU} \times \min (\mathrm{HPR})$ : } \\
\hline Gender (female vs. male) & 0.319 & 0.139 & 0.731 & 0.007 \\
\hline Age [years] & 1.06 & 1.024 & 1.097 & 0.001 \\
\hline Smoking & 2.57 & 1.29 & 5.15 & 0.008 \\
\hline Platelet count [G/I] & 1.007 & 1.002 & 1.012 & 0.008 \\
\hline Stented segment length [mm] & 1.033 & 1.010 & 1.057 & 0.005 \\
\hline Inflation pressure [atm] & 0.862 & 0.772 & 0.963 & 0.009 \\
\hline Stented vessel (Cx vs. LAD) & 3.28 & 1.54 & 6.96 & 0.002 \\
\hline \multicolumn{5}{|l|}{ ADPtest < $188 \mathrm{AU} \times \min :$} \\
\hline Hypertension & 0.52 & 0.37 & 0.71 & $<0.0001$ \\
\hline Diabetes type 2 & 0.52 & 0.36 & 0.73 & $<0.0001$ \\
\hline Smoking & 0.47 & 0.32 & 0.68 & $<0.0001$ \\
\hline Platelet count [G/l] & 0.99 & 0.994 & 0.999 & 0.028 \\
\hline \multicolumn{5}{|l|}{ ASPItest > $203 \mathrm{AU} \times \min (\mathrm{HAR}):$} \\
\hline Gender (women vs. men) & 2.07 & 1.22 & 3.5 & 0.007 \\
\hline Smoking & 2.58 & 1.58 & 4.23 & $<0.0001$ \\
\hline Stented segment length [mm] & 1.024 & 1.005 & 1.042 & 0.011 \\
\hline
\end{tabular}

$C X$ - circumflex branch, $L A D$ - left anterior descending branch. 
There is conflicting evidence as to the clinical risk factors related to poorer patient response to clopidogrel and aspirin. This study confirms predominant data indicating that higher age and type 2 diabetes are independent predictors of HPR. Other main findings are as follows: the diagnosis of hypertension is correlated with poorer response to clopidogrel; stented segment length is a predictor of HPR, while stent inflation pressure is actually a predictor of better clopidogrel response. Unexpectedly, we found that women in the studied cohort had a better response to clopidogrel than men and that active smoking is also linked to HPR.

Contrary to clopidogrel response, women were more likely to exhibit an inadequate response to aspirin. Other predictors of inadequate response to aspirin were smoking and stented segment length.

We found no new specific factors predisposing to enhanced clopidogrel response.

It is interesting how variably the risk factors of HPR have been described in the literature. The least controversy is associated with age [25-27], diabetes mellitus [28-31] and smoking. Active smoking has been found to be an independent predictor of better clopidogrel response, explained by the drug's pharmacodynamics [32-36], the so-called "smoker's paradox". However, we found a poorer smokers' clopidogrel response in our cohort, both for clopidogrel and aspirin, as have others [22, 33]. Smoking was also found to have no influence on clopidogrel response in some studies [25, 37]. However, as available data quite convincingly and predominantly confirm that smoking enhances platelet response to clopidogrel, how can we explain our results? We measured clopidogrel response in hospitalized patients, several days after admission. They had therefore not been smoking for at least three to 5 days preceding platelet reactivity testing. Hence, the metabolic influence of cigarette smoke on cytochrome P450 isoenzyme CYP1A2 may have ceased [38]. Alternatively, albeit unlikely, our results may reflect genetic differences of the studied cohort compared to other patient groups.

We found that women were more likely to respond better to clopidogrel than men, but less likely to respond well to aspirin. Some authors have found no association between gender and antiplatelet drug response [39], while others reported greater prevalence of HPR in women [40]. Similarly, our finding that hypertension increased the odds of HPR may be confirmed in the literature [30, 41], but one may also find evidence to testify otherwise [42]. In our study we did not find a relation of renal function to HPR or HAR, similarly to some authors [43], yet unlike other data, including our earlier study in a different cohort [44-47], possibly due to a low percentage of patients with significantly impaired renal function (eGFR below $30 \mathrm{ml} / \mathrm{min} / 1.73 \mathrm{~m}^{2}$ ). We have also recently documented that diabetic ACS patients have a higher risk of HPR-related stent thrombosis and death [48]. However, in the present study, ACS occurrence was not independently linked to HPR.

We were able to demonstrate in this study that stented segment length is independently related to HPR in the case of both clopidogrel and aspirin. Stented segment length may be considered a marker of increased and more diffuse atherosclerosis. Our data would therefore accord with an earlier study demonstrating that increased plaque burden is associated with high platelet reactivity on clopidogrel treatment [49]. It is more difficult to relate to our finding that stent inflation pressure is inversely related to the incidence of HPR; we are unable at present to provide a plausible cause of this finding. It would seem that greater inflation pressures, if anything, would also be a marker of increased atherosclerosis and calcification, so the association should in theory be similar to that observed for stented segment length. Of course, one may speculate that lower inflation pressures lead to higher incidence of malposition resulting in increased platelet activation and possibly stent thrombosis, a problem now widely discussed in BVS trials [50]. That, however, seems a somewhat farfetched idea, as local platelet activation would unlikely be detectable by MEA.

An interesting observation is the fact that in a controlled setting of in-hospital clopidogrel administration we found that only $6 \%$ of patients exhibited HPR. This is less than the usually described percentage of $10 \%$ to over $30 \%$, as observed in other studies [51]. However, in a recently published observation the incidence of HPR on clopidogrel was only $16 \%$, which is also a low value considering the acute coronary syndrome setting in that study [52]. On the other hand, while HPR on prasugrel and ticagrelor is generally $1-5 \%$, there are new observations indicating it may be as high as $13 \%$ in some cohorts [53].

Our aim was to attempt to clinically define the population in whom platelet reactivity monitoring and tailored therapy may be of value. We hoped to define risk factors that could possibly be incorporated into a risk score, an idea similar to that of the authors of the PREDICT-STABLE trial [54]. We found that age, hypertension, diabetes and smoking predispose to higher platelet aggregation values, as does longer stented segment length and lower stent inflation pressure. However, due to the variability of HPR risk factors in the literature, developing a risk score seems exceedingly difficult. The variability of factors influencing clopidogrel response across studies over a number of years may be due to different cohort characteristics, different platelet reactivity assessment methods and confounding factors, such as patient compliance $[55,56]$. This phenomenon may also explain why platelet function testing has failed to prove efficacious in randomized clinical trials. However, overwhelming observational evidence generally shows that inadequate platelet inhibition by DAPT results in increased risk of stent thrombosis and patient death $[55,57]$. That is why we really need to 
know how to reliably measure platelet reactivity, which tests are of value and whom to test - namely, what the characteristics of the population at risk are. The present study adds to this. However, data heterogeneity suggests that in order to develop a risk score, pooling of data from numerous studies is required. There have been the first, very interesting attempts at this approach [58], but more large meta-analyses are probably underway.

The study design precludes any causal relationship inferences. The studied group was medium-sized and somewhat heterogeneous - some relevant subgroups were underrepresented or missing, such as renal failure patients or type 1 diabetes patients. Only one method of platelet reactivity assessment was used. The number of variables tested for association with clopidogrel and aspirin response in the study was limited.

\section{Conclusions}

We found that in $\mathrm{PCl}$ patients on clopidogrel and aspirin, age, hypertension, diabetes and smoking predispose to higher platelet aggregation values, as does longer stented segment length and lower stent inflation pressure. If based on these data one was to suggest a subgroup of patients in whom to monitor platelet aggregation during aspirin and clopidogrel treatment, it would comprise older patients with diabetes and hypertension, actively smoking, with long stent-treated lesions.

\section{Acknowledgments}

The study was financed by National Science Centre grants NN 402381438 and NN 403397239.

\section{Conflict of interest}

The authors declare no conflict of interest.

\section{References}

1. Roffi M, Patrono C, Collet JP, et al. 2015 ESC Guidelines for the management of acute coronary syndromes in patients presenting without persistent ST-segment elevation: Task Force for the Management of Acute Coronary Syndromes in Patients Presenting without Persistent ST-Segment Elevation of the European Society of Cardiology (ESC). Eur Heart J 2016; 37: 267-315.

2. Levine GN, Bates ER, Blankenship JC, et al. 2011 ACCF/AHA/SCAI guideline for percutaneous coronary intervention: a report of the American College of Cardiology Foundation/American Heart Association Task Force on Practice Guidelines and the Society for Cardiovascular Angiography and Interventions. J Am Coll Cardiol 2011; 58: e44-122.

3. Jneid H, Anderson JL, Wright RS, et al. 2012 ACCF/AHA focused update of the guideline for the management of patients with unstable angina/non-ST-elevation myocardial infarction: a report of the American College of Cardiology Foundation/American Heart Association Task Force on Practice Guidelines. J Am Coll Cardiol 2012; 60: 645-81.

4. Aradi D, Komócsi A, Price MJ, et al.; the Tailored Antiplatelet Treatment Study Collaboration. Efficacy and safety of intensified antiplatelet therapy on the basis of platelet reactivity testing in patients after percutaneous coronary intervention: systematic review and metaanalysis. Int J Cardiol 2013; 167: 2140-8.

5. Ochała A, Siudak Z, Legutko J, et al. Percutaneous interventions in cardiology in Poland in the year 2014. Summary report of the Association of Cardiovascular Interventions of the Polish Cardiac Society AISN PTK. Postep Kardiol Inter 2015; 11: 177-81.

6. Bernlochner I, Steinhubl S, Braun S, et al. Association between inflammatory biomarkers and platelet aggregation in patients under chronic clopidogrel treatment. Thromb Haemost 2010; 104: 1193-200.

7. Ahn SG, Lee SH, Yoon JH, et al. Different prognostic significance of high on-treatment platelet reactivity as assessed by the VerifyNow P2Y12 assay after coronary stenting in patients with and without acute myocardial infarction. J Am Coll Cardiol Intv 2012; 5: 259-67.

8. Bonello L, Camoin-Jau L, Armero S, et al. Tailored clopidogrel loading dose according to platelet reactivity monitoring to prevent acute and subacute stent thrombosis. Am J Cardiol 2009; 103: 5-10.

9. Hirsh J. Hyperactive platelets and complications of coronary artery disease. N Engl J Med 1987; 316: 1543-4.

10. Aradi D, Collet JP, Mair J, et al. Study Group on Biomarkers in Cardiology of the Acute Cardiovascular Care Association of the European Society of Cardiology; Working Group on Thrombosis of the European Society of Cardiology. Platelet function testing in acute cardiac care - is there a role for prediction or prevention of stent thrombosis and bleeding? Thromb Haemost 2015; 113: 221-30.

11. Gurbel PA, Bliden KP, Hiatt BL, O'Connor CM. Clopidogrel for coronary stenting: response variability, drug resistance, and the effect of pretreatment platelet reactivity. Circulation 2003; 107: 2908-13.

12. Campo G, Parrinello G, Ferraresi P, et al. Prospective evaluation of on-clopidogrel platelet reactivity over time in patients treated with percutaneous coronary intervention relationship with gene polymorphisms and clinical outcome. J Am Coll Cardiol 2011; 57: 2474-83.

13. Cuisset T, Frere C, Quilici J, et al. Glycoprotein IIb/IIla inhibitors improve outcome after coronary stenting in clopidogrel nonresponders: a prospective, randomized study. I Am Coll Cardiol Intv 2008; 1: 649-53.

14. Gurbel PA, Bliden KP, Hiatt BL, O'Connor CM. Clopidogrel for coronary stenting: response variability, drug resistance, and the effect of pretreatment platelet reactivity. Circulation 2003; 107: 2908-13.

15. Gurbel PA, Tantry US. An initial experiment with personalized antiplatelet therapy: the GRAVITAS trial. JAMA 2011; 305: 1136-7.

16. Gurbel PA, Tantry US. Do platelet function testing and genotyping improve outcome in patients treated with antithrombotic agents?: platelet function testing and genotyping improve outcome in patients treated with antithrombotic agents. Circulation 2012; 125: 1276-87.

17. Eshtehardi P, Windecker S, Cook S, et al. Dual low response to acetylsalicylic acid and clopidogrel is associated with myonecrosis and stent thrombosis after coronary stent implantation. Am Heart J 2010; 159: 891-8.

18. Hazarbasanov D, Velchev V, Finkov B, et al. Tailoring clopidogrel dose according to multiple electrode aggregometry decreases the rate of ischemic complications after percutaneous coronary intervention. J Thromb Thrombolysis 2012; 34: 85-90. 
19. Sibbing D, Schulz S, Braun S, et al. Antiplatelet effects of clopidogrel and bleeding in patients undergoing coronary stent placement. J Thromb Haemost 2010; 8: 250-6.

20. Windecker S, Kolh P, Alfonso F, et al. 2014 ESC/EACTS Guidelines on myocardial revascularization: The Task Force on Myocardial Revascularization of the European Society of Cardiology (ESC) and the European Association for Cardio-Thoracic Surgery (EACTS) Developed with the special contribution of the European Association of Percutaneous Cardiovascular Interventions (EAPCI). Eur Heart J 2014; 35: 2541-619.

21. Levine GN, Bates ER, Bittl JA, et al. 2016 ACC/AHA Guideline Focused Update on Duration of Dual Antiplatelet Therapy in Patients With Coronary Artery Disease: A Report of the American College of Cardiology/American Heart Association Task Force on Clinical Practice Guidelines: An Update of the 2011 ACCF/AHA/ SCAI Guideline for Percutaneous Coronary Intervention, 2011 ACCF/AHA Guideline for Coronary Artery Bypass Graft Surgery, 2012 ACC/AHA/ACP/AATS/PCNA/SCAI/STS Guideline for the Diagnosis and Management of Patients With Stable Ischemic Heart Disease, 2013 ACCF/AHA Guideline for the Management of ST-Elevation Myocardial Infarction, 2014 AHA/ACC Guideline for the Management of Patients With Non-ST-Elevation Acute Coronary Syndromes, and 2014 ACC/AHA Guideline on Perioperative Cardiovascular Evaluation and Management of Patients Undergoing Noncardiac Surgery. Circulation 2016; 134: e123-55.

22. Sibbing D, Braun S, Morath T, et al. Platelet reactivity after clopidogrel treatment assessed with point-of-care analysis and early drug-eluting stent thrombosis. J Am Coll Cardiol 2009; 53: 849-56.

23. Gerotziafas GT, Zarifis J, Bandi A, et al. Description of response to aspirin and clopidogrel in outpatients with coronary artery disease using multiple electrode impedance aggregometry. Clin Appl Thromb Hemost 2012; 18: 356-63.

24. Tantry US, Bonello L, Aradi D, et al. Working Group on On-Treatment Platelet Reactivity. Consensus and update on the definition of on-treatment platelet reactivity to adenosine diphosphate associated with ischemia and bleeding. J Am Coll Cardiol 2013; 62: 2261-73.

25. Cho JH, Jeong YH, Ahn YJ, et al. The impact of smoking on post-clopidogrel platelet reactivity in patients with acute myocardial infarction. Korean Circ J 2010; 40: 119-24.

26. Verdoia M, Pergolini P, Rolla R, et al. Advanced age and high-residual platelet reactivity in patients receiving dual antiplatelet therapy with clopidogrel or ticagrelor. J Thromb Haemost 2016; 14: 57-64.

27. Xhelili E, Eichelberger B, Kopp CW, et al. The Antiplatelet effect of clopidogrel decreases with patient age. Angiology 2016; 67: 902-8.

28. Carreras ET, Hochholzer W, Frelinger AL $3^{\text {rd }}$, et al. Diabetes mellitus, CYP2C19 genotype, and response to escalating doses of clopidogrel. Insights from the ELEVATE-TIMI 56 Trial. Thromb Haemost 2016; 116: 69-77.

29. Feldman L, Tubach F, Juliard JM, et al. Impact of diabetes mellitus and metabolic syndrome on acute and chronic on-clopidogrel platelet reactivity in patients with stable coronary artery disease undergoing drug-eluting stent placement. Am Heart J 2014; 168: 940-7.

30. Tekkeşin Ai, Kaya A, Çakıllı Y, et al. The first six-month clinical outcomes and risk factors associated with high on-treatment platelet reactivity of clopidogrel in patients undergoing coronary interventions. Anatol J Cardiol 2016; 16: 967-73.
31. Angiolillo DJ, Jakubowski JA, Ferreiro JL, et al. Impaired responsiveness to the platelet $\mathrm{P} 2 \mathrm{Y} 12$ receptor antagonist clopidogrel in patients with type 2 diabetes and coronary artery disease. J Am Coll Cardiol 2014; 64: 1005-14.

32. Ueno M, Ferreiro JL, Desai B, et al. Cigarette smoking is associated with a dose-response effect in clopidogrel-treated patients with diabetes mellitus and coronary artery disease: results of a pharmacodynamic study. JACC Cardiovasc Interv 2012; 5: 293-300.

33. Gremmel T, Steiner S, Seidinger D, et al. Smoking promotes clopidogrel-mediated platelet inhibition in patients receiving dual antiplatelet therapy. Thromb Res 2009; 124: 588-91.

34. Patti G, Polacco $M$, Taurino $E$, et al. Effects of cigarette smoking on platelet reactivity during P2Y12 inhibition in patients with myocardial infarction undergoing drug-eluting stent implantation: results from the prospective cigarette smoking on platelet reactivity (COPTER) study. J Thromb Thrombolysis 2016; 41: 648-53.

35. Reed GW, Cannon CP, Waalen J, et al. Influence of smoking on the antiplatelet effect of clopidogrel differs according to clopidogrel dose: insights from the GRAVITAS trial. Catheter Cardiovasc Interv 2017; 89: 190-8.

36. Swiger KJ, Yousuf O, Bliden KP, et al. Cigarette smoking and clopidogrel interaction. Curr Cardiol Rep 2013; 15: 361.

37. Hochholzer W, Trenk D, Mega JL, et al. Impact of smoking on antiplatelet effect of clopidogrel and prasugrel after loading dose and on maintenance therapy. Am Heart J 2011; 162: 518-26.e5.

38. Lee HY, Kang HJ, Koo BK, et al. Enhanced clopidogrel response in smokers is reversed after discontinuation as assessed by VerifyNow assay: additional evidence for the concept of 'smokers' paradox'. Heart 2012; 98: 1000-6.

39. Verdoia M, Pergolini P, Rolla R, et al. Novara Atherosclerosis Study Group (NAS). Gender differences in platelet reactivity in patients receiving dual antiplatelet therapy. Cardiovasc Drugs Ther 2016; 30: 143-50.

40. Price MJ, Nayak KR, Barker CM, et al. Predictors of heightened platelet reactivity despite dual-antiplatelet therapy in patients undergoing percutaneous coronary intervention. Am J Cardiol 2009; 103: 1339-43.

41. Akturk IF, Caglar FN, Erturk M, et al. Hypertension as a risk factor for aspirin and clopidogrel resistance in patients with stable coronary artery disease. Clin Appl Thromb Hemost 2014; 20: 749-54.

42. Al-Azzam SI, Alzoubi KH, Khabour OF, et al. Factors that contribute to clopidogrel resistance in cardiovascular disease patients: environmental and genetic approach. Int J Clin Pharmacol Ther 2013; 51: 179-86.

43. Mayer K, Bernlochner I, Braun S, et al. Aspirin treatment and outcomes after percutaneous coronary intervention: results of the ISAR-ASPI registry. J Am Coll Cardiol 2014; 64: 863-71.

44. Barbieri L, Pergolini P, Verdoia M, et al.; Novara Atherosclerosis Study Group. Platelet reactivity in patients with impaired renal function receiving dual antiplatelet therapy with clopidogrel or ticagrelor. Vascul Pharmacol 2016; 79: 11-5.

45. Park SH, Kim W, Park CS, et al. A comparison of clopidogrel responsiveness in patients with versus without chronic renal failure. Am J Cardiol 2009; 104: 1292-5.

46. Kukula K, Klopotowski M, Kunicki P, et al. Platelet aggregation and the risk of stent thrombosis or bleeding in elective percutaneous coronary intervention patients. Blood Coagul Fibrinolysis 2017; 28: 383-8. 
47. Park KW, Park JJ, Jeon KH, et al. Clinical predictors of high posttreatment platelet reactivity to clopidogrel in Koreans. Cardiovasc Ther 2012; 30: 5-11.

48. Kukula K, Klopotowski M, Kunicki PK, et al. Platelet aggregation and risk of stent thrombosis or bleeding in interventionally treated diabetic patients with acute coronary syndrome. BMC Cardiovasc Disord 2016; 16: 252.

49. Chirumamilla AP, Maehara A, Mintz GS, et al. High platelet reactivity on clopidogrel therapy correlates with increased coronary atherosclerosis and calcification: a volumetric intravascular ultrasound study. JACC Cardiovasc Imaging 2012; 5: 540-9.

50. Ellis SG, Kereiakes DJ, Metzger DC, et al.; ABSORB III Investigators. Everolimus-eluting bioresorbable scaffolds for coronary artery disease. N Engl J Med 2015; 373: 1905-15.

51. Wisman PP, Roest M, Asselbergs FW, et al. Platelet-reactivity tests identify patients at risk of secondary cardiovascular events: a systematic review and meta-analysis. J Thromb Haemost 2014; 12: 736-47.

52. Lee S, Hizoh I, Kovacs A, et al. Predictors of high on-clopidogrel platelet reactivity in patients with acute coronary syndrome. Platelets 2016; 27: 159-67.

53. Verdoia M, Sartori C, Pergolini P, et al.; Novara Atherosclerosis Study Group (NAS). Prevalence and predictors of high-on treatment platelet reactivity with ticagrelor in ACS patients undergoing stent implantation. Vascul Pharmacol 2016; 77: 48-53.

54. Droppa M, Tschernow D, Müller KA, et al. Evaluation of clinical risk factors to predict high on-treatment platelet reactivity and outcome in patients with stable coronary artery disease (PREDICT-STABLE). PLoS One 2015; 10: e0121620.

55. Winter MP, Koziński M, Kubica J, et al. Personalized antiplatelet therapy with P2Y12 receptor inhibitors: benefits and pitfalls. Postep Kardiol Inter 2015; 11: 259-80.

56. Gasparyan AY, Watson T, Lip GY. The role of aspirin in cardiovascular prevention: implications of aspirin resistance. J Am Coll Cardiol 2008; 51: 1829-43.

57. Thomas MR, Storey RF. Clinical significance of residual platelet reactivity in patients treated with platelet $\mathrm{P} 2 \mathrm{Y} 12$ inhibitors. Vascul Pharmacol 2016; 84: 25-7.

58. Reny JL, Fontana P, Hochholzer W, et al. Vascular risk levels affect the predictive value of platelet reactivity for the occurrence of MACE in patients on clopidogrel. Systematic review and metaanalysis of individual patient data. Thromb Haemost 2016; 115: 844-55. 